O ano de 2003 foi, salvo melhor juízo, um marco para a Psicopatologia Fundamental.

A criação da Associação Universitária de Pesquisa em Psicopatologia Fundamental, ocorrida em maio, consolida e organiza um esforço coletivo iniciado no começo de 1998, com a Rede Universitária de Pesquisa em Psicopatologia Fundamental e com os diversos Congressos Brasileiros de Psicopatologia Fundamental iniciados em 1996.

A Associação, sociedade civil sem fins lucrativos, reúne, hoje, 41 professores doutores de 21 Universidades brasileiras. Congrega, sem dúvida nenhuma, elite de pesquisadores científicos brasileiros dedicados ao ensino e à pesquisa no campo do pathos psíquico. Além disso, reúne pesquisadores de alto nível de Universidades da Argentina, do Uruguai, do México e da França. Trata-se, portanto, de uma instituição internacional.

A produção científica desse grupo de pesquisadores é notável. Muitos deles dirigem Laboratórios de Psicopatologia Fundamental em suas respectivas Universidades. Assim, só no Brasil, há, atualmente, seis Laboratórios, na Universidade Federal do Pará - UFPA, na Universidade Católica de Pernambuco - Unicap, na Universidade Estadual Paulista Unesp, na Universidade Estadual de Campinas - Unicamp, na Pontifícia Universidade Católica de São Paulo - PUC-SP, na Universidade Federal do Rio Grande do Sul - UFRGS. Outros 
pesquisadores, membros da Associação, dirigem excelentes grupos permanentes de pesquisa que receberam outros nomes, como a Pré-Escola Terapêutica Lugar de Vida, do Instituto de Psicologia da Universidade de São Paulo - USP, o Sephora, do Instituto de Psicologia da Universidade Federal do Rio de Janeiro ou o Núcleo de Estudos em Desenvolvimento Humano - NEDHU, do Departamento de Psicologia da Universidade Federal do Paraná. Trata-se, pois, de uma Associação que reúne líderes de grupos. Isso, também, é verdade no plano internacional, onde o Prof. Dr. Roland Gori dirige o Centre Inter-régional de Recherches en Psychopathologie Clinique.

O número, e principalmente a qualidade de dissertações de Mestrado e de teses de Doutorado produzidas por pesquisadores sob orientação de membros da Associação, é bastante animador e crescente. Procura-se, dessa forma, criar e desenvolver uma capacidade cada vez maior de produção do conhecimento, visando o tratamento psicoterapêutico do sofrimento psíquico e um certo bemestar relativo da população num mundo evidentemente inóspito.

Diversos pesquisadores são editores responsáveis de periódicos científicos de renome como a Cliniques Méditerranéenes, a Psicologia Clínica, a Tempo Psicanalítico, Estilos da Clínica, Pulsional Revista de Psicanálise e a Revista Latinoamericana de Psicopatologia Fundamental. O número de livros e de artigos publicados em revistas científicas nacionais e internacionais é bastante significativo e crescente. A produção escrita em co-autoria ainda deixa a desejar, mas está num crescendo. Pesquisas em co-autoria ainda são praticamente inexistentes, mas começa a ocorrer uma interlocução estimulante e produtiva em torno das próprias pesquisas em andamento. Essa interlocução científica entre os membros da Associação é importante e deve ser estimulada, pois só assim haverá um progresso em nosso conhecimento.

Talvez o aspecto mais importante dessa produção científica seja o da recuperação mesmo da psicopatologia como um discurso (logos) a respeito do pathos psíquico que vinha se perdendo em função de uma prática diagnóstica mecanicamente aplicada no paciente, que acabava por cronificar a doença mental e matava a longa e rica tradição psicopatológica que leva em consideração o discurso do paciente, a dimensão subjetiva do pathos psíquico e sua compreensão psicoterapêutica, ou seja, uma compreensão que contém, em si, um tratamento. Além disso, tomando o medicamento como um recurso enigmático do tratamento psicoterapêutico, a Psicopatologia Fundamental evita a produção de toxicomanias assistidas e recupera a possibilidade de transformar a vivência mórbida em experiência vital.

Além disso, partindo do pressuposto de que ninguém possui um conhecimento acabado sobre o pathos psíquico, a Psicopatologia Fundamental acolhe e estimula a interlocução inteligente entre diferentes - médicos, psicólogos, 
psicanalistas, filósofos, jornalistas etc. - visando o enriquecimento dos conhecimentos sustentados por esses diversos especialistas. Cria-se, dessa forma, um ambiente extremamente estimulante para a investigação, a interlocução e a escrita, condições necessárias para a produção científica significativa.

O VII Encontro Científico da Associação Universitária de Pesquisa em Psicopatologia Fundamental, realizado em Petrópolis, RJ, de 4 a 7 de setembro deste ano é testemunha eloqüente da excelente qualidade da produção deste grupo. Nele compareceram 29 pesquisadores e foram comentados 27 trabalhos escritos, previamente distribuídos e lidos pelos participantes. Essa interlocução privilegiada, ocorrida num clima afável e descontraído propício ao pensamento, é prova de que é possível reunir estudiosos que possuem diferentes pontos de vista sobre determinados assuntos, sendo possível uma interlocução voltada para a inteligência dos fenômenos examinados. Sustentar uma posição é, muitas vezes, tão difícil quanto assegurar a palavra do outro visando a compreensão de um fenômeno que interessa a todos. Entretanto, é isso que tem ocorrido nos Encontros Científicos promovidos pela Associação.

Com a criação da Associação, a Revista Latinoamericana de Psicopatologia Fundamental passou a ser seu órgão oficial. Com a publicação deste quarto número do volume VI, a Revista consolida sua posição de publicação científica com verdadeira vocação internacional. Em 2003 foi avaliada, pela terceira vez consecutiva, como publicação "Nacional - A” pela Associação Nacional de PósGraduação e Pesquisa em Psicologia - ANPEPP/Fundação Coordenação do Aperfeiçoamento do Pessoal de Nível Superior - Capes. Trata-se, portanto, de periódico de excelente nível científico e editorial. O número de assinantes e, principalmente, de citações de trabalhos publicados na Revista em dissertações, teses, livros e artigos, revela que se trata de publicação de grande impacto científico.

Visando ampliar os horizontes da Psicopatologia Fundamental, a Revista Latinoamericana de Psicopatologia Fundamental apresentará importantes modificações editoriais em 2004, incluindo seções de história da psiquiatria, de saúde mental e uma seção denominada Observando a psiquiatria.

A Associação Universitária de Pesquisa em Psicopatologia Fundamental inscreveu-se como instituição no CNPq e está empenhada, agora, na realização do I Congresso Internacional de Psicopatologia Fundamental e VII Congresso Brasileiro de Psicopatologia Fundamental que será realizado na Pontifícia Universidade Católica o Rio de Janeiro - PUC-RJ, de 4 a 7 de setembro de 2004.

Esse Congresso, com a presença já confirmada de pesquisadores da Argentina, Uruguai, Brasil, México, EUA, França e Austrália será um momento de grande importância para a pesquisa, o ensino e a extensão da Psicopatologia Fundamental e, certamente, confirmará o positivo ambiente de trabalho ocorrido 
nos anteriores Congressos da especialidade, especialmente o de 2000 na Unicamp e o de 2002 promovido pela Universidade Católica de Pernambuco - Unicap, em Recife, Pernambuco.

Durante o Congresso, será premiado o trabalho vencedor do Concurso Internacional Pierre Fédida de Ensaios Inéditos de Psicopatologia Fundamental, no valor de R\$2.000,00 (dois mil reais) ou US\$ 700.00 (setecentos dólares) com direito à publicação na Revista Latinoamericana de Psicopatologia Fundamental. Esse prêmio visa estimular a produção escrita de jovens pesquisadores no campo da Psicopatologia Fundamental.

Todas essas iniciativas decorrem de um empenho coletivo dos pesquisadores membros da Associação, que se dedicam com afinco à pesquisa, ao ensino e à extensão, apesar das condições bastante precárias em que se encontram as Universidades em praticamente todo o mundo Ocidental, com exceção, talvez, das dos EUA e da Inglaterra.

É, pois, com grande orgulho e satisfação que festejo o ano de 2003 apresentando ao público leitor algumas de nossas conquistas e realizações neste profícuo período.

São Paulo, dezembro de 2003.

Prof. Dr. Manoel Tosta Berlinck Presidente Associação Universitária de Pesquisa em Psicopatologia Fundamental

\section{Nota da redação}

Este número da Revista Latinoamericana de Psicopatologia Fundamental homenageia os 50 anos de existência do Hospital Psiquiátrico de Jurujuba, de Niterói, RJ, e o trabalho que vem sendo ali realizado, e um eloqüente testemunho de que é possível realizar uma passagem paradigmática na psiquiatria e na medicina hospitalar sem provocar a destruição da instituição, ainda tão necessária, tendo em vista as características de nossa sociedade desigual e combinada.

Estão reunidos aqui texto de Eduardo Carvalho Rocha e uma entrevista com ele, atual diretor desse Hospital. 